SCIO. Revista de Filosofia, n. ${ }^{\circ}$ 19, Noviembre de 2020, 63-99, ISSN: 1887-9853

\title{
REFUGIADOS CLIMÁTICOS, VULNERABILIDAD Y PROTECCIÓN INTERNACIONAL
}

\author{
CLIMATE REFUGEES, VULNERABILITY AND \\ INTERNATIONAL PROTECTION
}

Teresa Vicente Giménez ${ }^{a^{*}}$

Fechas de recepción y aceptación: 21 de julio de 2020 y 14 de octubre de 2020

DOI: $10.46583 /$ scio_2020.19.694

Resumen: La cifra sobre desplazamiento forzoso en el mundo alcanza máximos históricos, y se verá incrementada en el futuro debido al desplazamiento humano que provoca el calentamiento del planeta y la degradación ecológica que caracteriza la actual era del Antropoceno. La protección internacional que otorga el derecho a las personas que huyen de sus tierras y buscan refugio está relacionada con la exposición a peligros, la vulnerabilidad y la dificultad de estas personas para ejercer sus derechos humanos. La movilidad por causas ambientales provoca nuevos motivos de protección jurídica no previstos en la Convención sobre el estatuto de los refugiados, pero a la que hay que dar respuesta y solución. En el siglo xxi Naciones Unidas consolida un nuevo enfoque de los derechos humanos con relación al cambio climático y las migraciones, y este paradigma debe resolver el vacío de la doctrina jurídica tradicional para abordar el problema de las migraciones climáticas. También se encuentran en situación de vulnerabilidad, junto a las mujeres

\footnotetext{
${ }^{a}$ Departamento de Fundamentos del Orden Jurídico y Constitucional. Área de Filosofía del Derecho. Universidad de Murcia.

* Correspondencia: Universidad de Murcia. Departamento de Fundamentos del Orden Jurídico y Constitucional. Área de Filosofía del Derecho. Calle Santo Cristo, 1. 38001 Murcia. España.

E-mail: teresavi@um.es
} 
y los menores, que sí son reconocidas y protegidas por el derecho, y los jóvenes varones refugiados, muchos de los cuales se ven abocados a ejercer la prostitución para sobrevivir. A la reflexión sobre los conceptos de refugiado/migración y al análisis de los nuevos motivos de vulnerabilidad por razones del cambio climático se dedica el presente trabajo, para evidenciar que el actual modelo migratorio de defensa de frontera actúa en sentido opuesto a la solución real de un movimiento creciente de personas vulnerables que deambula por el mundo en busca de refugio.

Palabras claves: refugiados climáticos, migrantes, vulnerabilidad, menores, mujeres, varones jóvenes, cambio climático, Antropoceno.

Abstract: The forced displacement in the world reaches historical maximums, and it will increase in the future due to the human displacement caused by global warming and the ecological degradation that characterizes the era of the Anthropocene. The international protection that the law gives to refugees is related to their exposure to dangers, vulnerability and difficulty in managing their human rights. Mobility due to environmental causes gives rise to new reasons for legal protection not provided for in the Convention of Refugees (1951), but which must be answered and resolved. In the 21 st century, the United Nations consolidated a new approach to human rights in relation to climate change and migration, and this paradigm must bridge the gap in traditional legal doctrine to resolve the problem of climate migration. Along with women and minors who are recognized and protected by law, young male refugees are also in a vulnerable situation, many of them being forced into prostitution to survive. This article aims to reflect on the terms "refugee" and "migration", and to analyse new reasons for vulnerability, so as to prove that the current migratory model of border defense runs counter to the real solution of a growing movement of vulnerable people who go around the world in search of refuge.

Keywords: climate refugees, migrants, refugees, minors, women, young men, climate change, Anthropocene. 


\section{§1. REFUGIO, VULNERABILIDAD Y NECESIDAD DE PROTECCIÓN ESPECÍFICA}

La cifra de desplazamiento forzado ha vuelto a alcanzar máximos históricos en 2019 a escala global. A finales de 2019, 79,5 millones de personas en todo el mundo han sido desplazadas por la fuerza, en comparación con los 70,8 millones del año anterior. De estos casi 80 millones de desplazados forzosos, hay 29,6 millones de personas refugiadas o desplazadas fuera de su país, y 45,7 millones de personas que han buscado seguridad en su propio país. Los países de donde provienen la mayor parte de las personas refugiadas del mundo son Siria, Palestina, Afganistán, Sudán del Sur, Myannar y Venezuela. Son los datos que se recogen en el informe sobre 2019 de ACNUR, la Agencia de la ONU para los refugiados, sobre Tendencias Globales (ACNUR, Informe 2020) ${ }^{1}$. Actualmente más del uno por ciento de la humanidad, 1 de cada 98 personas, huyen a consecuencia de la persecución, los conflictos, la violencia, las violaciones de derechos humanos, el cambio climático y los desastres naturales.

En los últimos 10 años más de 100 millones de personas se han visto obligadas a huir de sus hogares para buscar refugio dentro o fuera de las fronteras de su país. Las cifras sobre desplazamientos forzosos se han incrementado en las últimas décadas debido a los efectos adversos del cambio climático, y en un futuro aumentarán a un ritmo cada vez más acelerado, como señala la Agencia de la ONU para los Refugiados: "los científicos coinciden en que los actuales riesgos climáticos continuarán contribuyendo a incrementar el desplazamiento forzado en el futuro" (ACNUR, Cambio climático, Desastres y Desplazamientos, 2017) $)^{2}$.

De acuerdo con la Organización Internacional para las Migraciones (OIM), el número de migrantes climáticos podría alcanzar la cifra de 200 millones para el 2050. Aunque se trata de una predicción todavía hipotética, la cifra de 200 millones de migrantes climáticos calculada por el profesor Myers, en su trabajo Environmental refugees: An emergent security issue presentado en el decimotercer Foro Económico de Praga en mayo de 2005, es la que tiene

${ }^{1}<$ https://acnur.org/5eeaf5664\#_ga=2.124720137.2076242601.1593590645-58030701.1592906904>.

${ }^{2}<$ https://www.acnur.org/5d4c9b7f4.pdf $>$. 
mayor aceptación y la que se menciona en prestigiosas publicaciones desde el IPPCC hasta el Informe Sterm sobre la economía del cambio climático (Estudio n. ${ }^{0} 31$ sobre Migración y cambio climático de la OIM de 2008)³.

El desplazamiento interno también alcanza cifras alarmantes. Siria, que lleva 10 años de conflicto bélico, continúa siendo la mayor población desplazada por la fuerza en todo el mundo (13,2 millones, incluidos 6,6 millones de refugiados y más de seis millones de desplazados internos). Colombia es el país que tiene un mayor número de personas desplazadas dentro de sus fronteras (7,8 millones de personas).

A pesar de que los países más pobres del mundo continúan acogiendo a la mayoría de las personas refugiadas, en la Unión Europea, en 2019 el número de personas que buscaron refugio dentro de sus fronteras volvió a crecer y el Mediterráneo continúa siendo la ruta migratoria con más muertes del planeta. El problema no es una crisis de los refugiados, sino una crisis de la democracia, que de manera reaccionaria, simplista e ineficaz trata de responder al gran desafío que plantean los movimientos migratorios, como afirma Javier de Lucas: "hoy se ha incrementado la contradicción entre el universalismo moral y la condición de triage de todos los otros, precisamente en la medida que no sólo son prescindibles como argumenta Baumann al hablar de estos nuevos parias de la modernidad, sino piezas de las que disponemos a nuestro antojo en un recorte brutal de su derecho a la libertad de circulación" (De Lucas, 2015: 40-41).

En el momento actual, cuando se registran las cifras más elevadas de desplazamiento forzado global, la política migratoria actúa en sentido opuesto, con el cierre de fronteras, la reducción de las vías legales de acceso a la protección internacional, se obstaculiza el acceso a los derechos básicos de las personas migrantes y solicitantes de asilo y persisten los conflictos que están en la raíz de esta movilidad forzada de las personas. Estas cuestiones son analizadas en el informe anual 2020 de CEAR, la Comisión Española de Ayuda al Refugiado ${ }^{4}$.

${ }^{3}<$ https://publications.iom.int/system/files/pdf/mrs-31_sp.pdf $>$.

${ }^{4}<$ https://www.cear.es/informe-cear-2020/>. 
Las personas que se ven obligadas a dejar sus lugares de origen por temor a riesgos actuales y futuros de los impactos del cambio climático tienen dos posibilidades hacia dónde dirigirse: a los territorios de frontera, que nacen como un muro de contención de los movimientos migratorios de los territorios deprimidos hacia los más desarrollados. Estos son territorios estancos, un proceso de litoralización que deja como únicas alternativas la permanencia en el lugar de recepción o el regreso hacia el lugar de origen, algo absurdo por el deterioro ambiental irreversible de este espacio. La otra posibilidad para los refugiados climáticos es dirigirse a los países desarrollados o emergentes. Las representaciones sociales que tienen los grupos de acogida son las mismas que durante años se han ido construyendo: los peligros de la llegada masiva y la inestabilidad que supone la entrada de personas con modos de vida diferentes, los tópicos de que vienen a quitarnos el trabajo y que todos aquellos que no entran por conducto regular no son refugiados sino ilegales (Rivillo, 2016: 187-190).

La respuesta que da el derecho ante la vulnerabilidad y las necesidades de las personas que buscan refugio es otorgarles una protección jurídica internacional. El marco jurídico para reforzar la protección de los refugiados está constituido por el derecho internacional de los refugiados, el derecho internacional de los derechos humanos y el derecho internacional humanitario.

El derecho internacional ha reconocido a estas personas un derecho a solicitar asilo, entendiendo este término como sinónimo de protección. La Declaración Universal sobre Derechos Humanos de 10 de diciembre de 1948, en su artículo 14, reconoce a toda persona, en caso de persecución, el derecho a buscar asilo y a disfrutar de él en cualquier país; derecho al que también se refiere la Declaración sobre el Asilo Territorial de 14 de diciembre de 1967. Ahora bien, este derecho no se ha visto acompañado del derecho al asilo o la imposición de la obligación de otorgarlo, en cualquier caso.

Con anterioridad a la adopción de la Convención sobre el Estatuto de los Refugiados en 1951, la protección se dispensaba a través del asilo y este constituía una manifestación de la soberanía del Estado, que acogía discrecionalmente en su territorio a las personas que solicitaban su amparo. Correspondía, por tanto, a los Estados la prerrogativa de establecer las condiciones que debían reunir los solicitantes y determinar su estatuto jurídico (derechos y 
obligaciones derivados de la concesión de asilo); esta discrecionalidad del Estado solo encontraba un límite: la obligación derivada del principio de non refoulement. Este principio impone a los Estados la obligación de no devolver al solicitante de asilo o protección a ningún país donde su vida o su libertad corra peligro. En caso de no ser posible la devolución, el Estado está obligado a otorgar acogida y protección.

Con la adopción de la Convención sobre el Estatuto de los Refugiados de 1951, el refugio vino a unirse al asilo como forma de protección dispensada a quienes reunieran la condición de refugiado. Según este Convenio, tras la modificación establecida en 1967, se entiende por "persona refugiada" toda persona que, debido a fundados temores de ser perseguida por motivos de raza, religión, nacionalidad, pertenencia a un determinado grupo social u opiniones políticas, se encuentra fuera del país de su nacionalidad o residencia (apátridas) y no puede o, a causa de dichos temores, no quiere acogerse a la protección de tal país.

La definición de la Convención de 1951 sobre la condición de "refugiado" no incluye los factores ambientales; por ello la mayoría de los estudios, círculos académicos e iniciativas políticas, a pesar del uso constante del término "refugiados climáticos" para expresar la creciente movilidad humana por causa de desastres y cambio climático, no los reconocen. Sin embargo, frente al rechazo de la noción del "refugiado climático", existen importantes hallazgos en la investigación y en diferentes iniciativas prácticas de ámbito jurídico que tratan de ampliar el término de refugiado a un grupo más amplio de personas, para alcanzar la noción de refugio climático. En este sentido el jurista Matthew Scott, director del área "people on the move" del Instituto Raoul Wallenberg de Derechos Humanos y Derechos Humanitario en Lund (Suecia) e investigador colaborador del Instituto de Derechos Humanos Ludwig Boltzman, subraya la importancia de iniciativas como las de la Agenda 2015 para la protección de las personas desplazadas transfronterizas en el contexto de los desastres y el cambio climático, que elabora "prácticas eficaces" y propone "herramientas prácticas" para que los Estados puedan enfrentar la llegada y permanencia de personas desplazadas a través de las fronteras internacionales en el contexto de desastres y cambio climático (Scott, 2020). 
En el contexto de la protección internacional, hay que señalar también los instrumentos regionales sobre los refugiados, como la Convención de la Organización de la Unidad Africana por la que se regulan los aspectos específicos de los problemas de los refugiados en África y la Declaración de Cartagena sobre los Refugiados.

En Europa -y en España- las formas a través de las que se responde a la obligación de proteger son: asilo, para las personas refugiadas; protección subsidiaria, para las personas con temor a sufrir pena de muerte, torturas, amenazas para la vida o integridad física a consecuencia de situaciones de violencia indiscriminada o conflicto armado; la protección temporal, para los casos de afluencia masiva de refugiados como primera respuesta; y una protección humanitaria al amparo de legislación de extranjería, para supuestos en los que no se puede devolver a la persona y que no puedan ser incluidos en ninguna de las figuras anteriores. El marco legislativo vigente y la política de asilo en la Unión Europea se conocen como Sistema Europeo Común de Asilo (SECA). Dentro de este marco normativo, la protección temporal contemplada en la Directiva de Protección Temporal, podría haber sido una buena respuesta para la afluencia masiva de personas a las fronteras de Europa desde 2015, y también una solución para las personas desplazadas por catástrofes climáticas; sin embargo, no se ha utilizado nunca.

La posición de la Unión Europea en la lucha contra el cambio climático y su compromiso con el Pacto Verde Europeo de convertir a Europa en el primer continente neutro en emisiones en 2050 contrasta con la inexistencia de mecanismos de protección para los más afectados por la crisis ecológica y climática: los migrantes/refugiados climáticos, dos términos que en el glosario de la Organización Internacional de Inmigraciones no son sinónimos, la "migración" se usa para el desplazamiento tanto interno como externo de la población, y la "persona refugiada" corresponde a aquella que huye sin planificación alguna de su territorio debido a que su vida está amenazada. Como señala la jurista Beatriz Abellán, experta en derechos humanos y consultora de la Unión Europea en temas de diplomacia pública y cooperación, "la ausencia de mención a los migrantes por razones climáticas en la recién presentada Agencia Europa sobre Migraciones es una oportunidad perdida para 
la inclusión de una figura de protección expresa o la introducción de nuevas bases de protección" (Abellán, 2020).

La Asamblea General de las Naciones Unidas (ONU), un año después de la aprobación en 2015 de la Agenda 2030, y de que los Estados hayan firmado y ratificado el Acuerdo de París sobre el Cambio Climático, decide aprovechar este movimiento mundial por la justicia climática en favor de los refugiados y los migrantes, y reforzar la contribución positiva que hacen los migrantes al desarrollo sostenible. El 19 de septiembre de 2016 se adopta por la Asamblea General la Declaración de Nueva York sobre Refugiados y Migrantes, que reafirma la importancia del régimen de protección internacional de refugiados y establece las bases para la adopción de un Pacto Mundial para los Refugiados. El 17 de diciembre de 2018, la Asamblea General de las Naciones Unidas adoptó la resolución (A RES/73/151), que aprueba el Pacto Mundial sobre los Refugiados ${ }^{5}$; dicha resolución subraya la importancia del pacto mundial sobre los refugiados como "una representación de la voluntad política y la ambición de poner en práctica el principio de responsabilidad compartida, así como de movilizar a la comunidad internacional en su conjunto e impulsar la acción para mejorar la respuesta en situaciones de refugiados". La resolución hace un llamado "a la comunidad internacional en su conjunto, incluidos los Estados y otras partes interesadas pertinentes, para que apliquen el pacto mundial sobre los refugiados, mediante acciones, compromisos y contribuciones concretos, incluyendo el primer Foro Mundial sobre los Refugiados". El primer Foro Mundial sobre Refugiados se celebró en diciembre de 2019; sin embargo, las cifras de los desplazamientos forzosos siguen en aumento y las vías de solución se endurecen.

Los motivos de protección internacional pueden expresarse en relación con los peligros, la exposición y la vulnerabilidad. La vulnerabilidad se refiere a la predisposición de una persona a ser afectada negativamente, lo que incluye una variedad de conceptos y elementos, como la susceptibilidad al daño y la falta de capacidad para hacer frente y adaptarse. La vulnerabilidad también se puede entender como aquellas personas que se encuentran en una

\footnotetext{
${ }^{5}<$ https://www.unher.org/gcr/GCR_Spanish.pdf $>$.
} 
situación de desventaja frente a otras para reconocer y ejercer de manera efectiva sus derechos humanos.

El Pacto Mundial sobre los Refugiados de 2018 dentro de su programa de acción tiene en cuenta la vulnerabilidad y las necesidades de protección específica tanto de las mujeres y niñas, como de los niños, adolescentes y jóvenes. En relación con las mujeres y niñas, después de señalar los obstáculos específicos asociados a su género, insta a los Estados y las partes interesadas a procurar el empoderamiento de las mujeres y las niñas de las comunidades de refugiados y de acogida; procurar su pleno disfrute de los derechos humanos en condiciones de igualdad respecto a los hombres y los niños; y reforzar la capacidad de acción de las mujeres y de las niñas, promoviendo su empoderamiento económico y su acceso a la educación. Para ello se hace necesario promover la participación y el liderazgo real de las mujeres y las niñas, fomentando la capacidad institucional y la participación de organizaciones nacionales y comunitarias de mujeres y de los ministerios gubernamentales competentes; fortalecer el acceso a la justicia de las mujeres y las niñas y su seguridad y protección, en particular con objeto de prevenir y combatir todas las formas de violencia; y facilitar el acceso a los servicios sociales y de atención a la salud que tengan en cuenta el género.

En relación con los niños, adolescentes y jóvenes, se deben tener en cuenta las necesidades de protección específica de este grupo vulnerable: las niñas y los niños, los niños con discapacidad, los adolescentes, los niños no acompañados y separados de sus familias, los supervivientes de la violencia sexual y de género, la explotación y los abusos sexuales y las prácticas nocivas, y otros niños en situación de riesgo. En este sentido, los Estados y las partes interesadas, como Unicef y las sociedades civiles pertinentes, aportarán recursos y conocimientos para cubrir las necesidades específicas de los niños y niñas y, para apoyar la participación activa de los jóvenes, de las comunidades de refugiados y de acogida.

El cambio climático tiene que ver también con la vulnerabilidad de las personas. Cuando la vulnerabilidad aumenta, significa que una persona puede tener menor capacidad de adaptarse o de responder a los efectos del cambio climático. Los fenómenos climáticos repercutirán en mayor medida en aquellas personas que se encuentran en situaciones vulnerables por su geografía, 
género, edad o condición, como señala el informe Los efectos de evolución lenta del cambio climático y la protección de los migrantes transfronterizos del Alto Comisionado de las Naciones Unidas para los Derechos Humanos (ACNUDH, 2018) $)^{6}$.

Teniendo en cuenta la dificultad que tienen las personas obligadas a desplazarse por los desastres naturales y el cambio climático para ejercer sus derechos, la movilidad por causas ambientales provoca nuevos motivos de protección no incluidos en la Convención de Ginebra, a los que hay que dar respuesta y protección internacional. Para afrontar este nuevo reto cabía imaginar dos soluciones: por un lado, la modificación del concepto de refugiado; por otro, el establecimiento de una nueva forma de protección con un estatuto jurídico propio.

\section{§2. Refugiados, DesplaZAdos o MigRANTES CLIMÁticos}

La evidencia científica afirma que el cambio climático es real y que se espera que altere la variabilidad normal en el clima y que haga que los fenómenos meteorológicos extremos y los desastres naturales sean más graves y frecuentes. Uno de los peligros más graves que conlleva el cambio climático podría ser la migración humana forzosa, como advirtió en 1990 el IPCC (Grupo Intergubernamental de Expertos sobre el Cambio Climático). Los científicos del clima del Panel Intergubernamental sobre el Cambio Climático, en su 5. Informe de Evaluación (IPCC de 2014), confirman que el cambio climático es real, identifican la creciente frecuencia de fenómenos meteorológicos extremos y desastres naturales, el aumento del nivel del mar, las inundaciones, las olas de calor, las sequías, la desertificación, la escasez de agua y la propagación de enfermedades tropicales como algunos de los efectos adversos del mismo, y afirman inequívocamente que estos fenómenos amenazan directa e indirectamente el disfrute pleno y efectivo de los derechos humanos de las personas de todo el mundo, incluidos los derechos a la vida,

\footnotetext{
$6<$ https://disasterdisplacement.org/portfolio-item/los-efectos-de-evolucion-lenta-del-cambioclimatico-y-la-proteccion-de-los-migrantes-transfronterizos>.
} 
el agua y el saneamiento, la alimentación, la salud, la vivienda, la autodeterminación, la cultura y el desarrollo.

El cambio climático no solo aumenta la probabilidad de que las personas se desplacen, sino que también afecta a su seguridad y derechos humanos durante su desplazamiento y los obstáculos que enfrentan en sus esfuerzos para lograr soluciones duraderas. En el informe mundial de 2019 del IDMC (Centro para el Monitoreo del Desplazamiento Interno, Consejo Noruego para los Refugiados) se señala que el desplazamiento pone a las personas en mayor riesgo de empobrecimiento y discriminación, y aunque las vulnerabilidades de los desplazados internos difieren de una situación a otra, la inseguridad es solo un componente de la severidad del desplazamiento, otros factores son el acceso a una vivienda, servicios, medios de subsistencia, documentación, reunificación familiar, asuntos públicos o justicia. (Informe Mundial sobre Desplazamiento Interno 2019$)^{7}$.

A partir del 2005, Naciones Unidas ha ido consolidando el nuevo enfoque del cambio climático basado en los derechos humanos, y ha reconocido las relaciones entre este fenómeno y las migraciones. Hasta ese momento el cambio climático y los derechos humanos se habían mantenido separados desde el punto de vista legal.

El primer caso que se planteó para reclamar protección de los derechos humanos, directamente ligado al calentamiento global, fue en 2005 por los pueblos indígenas del Ártico. El banco de hielo del Círculo Polar Ártico se funde cada vez más rápido, lo que acarrea la codicia del dominio de nuevas vías de navegación, los recursos petrolíferos, de gas, halientiques, minas de uranio, minerales preciosos y tierras que ahora son accesibles gracias al deshielo. El 7 de diciembre de 2005 se presentó a la Comisión Interamericana de Derechos Humanas (IAComHR) una solicitud o demanda por parte del Consejo de los Inuit del Círculo Polar Ártico, en nombre de todas las regiones árticas de Estados Unidos y Canadá. Esta demanda fue dirigida contra los Estados Unidos de América, por violaciones de derechos humanos resultado del calentamiento global causado por sus actos y omisiones, donde le pidieron a la Comisión que declarase a los EE. UU. responsable, conforme a

\footnotetext{
${ }^{7}<$ https://www.internal-displacement.org/sites/default/files/inline-files/2019-IDMC-GRID-sp.pdf $>$.
} 
la Declaración Americana de derechos y obligaciones del hombre, y que les inste a encontrar una solución adecuada de cooperación mediante la adopción de medidas de mitigación y adaptación del cambio climático. Su petición fue rechazada, pero los indígenas del Ártico fueron escuchados en audiencia pública en 2007.

El caso de los Inuit fue un ejemplo que se siguió, y de hecho el 23 de abril de 2013 el Consejo de los Athabaskan del Ártico (AAC) interpone una solicitud ante la Comisión Interamericana de derechos humanos (IAcomHR) contra Canadá por las emisiones de carbono que provocan el calentamiento y el deshielo del Ártico, para que Canadá adopte medidas que limiten las emisiones en sectores claves y que se coordine con los Athabaskan para elaborar un plan sobre la pérdida de recursos y de cultura por los efectos del deshielo acelerado por las emisiones de carbono.

Desde esta nueva perspectiva de las relaciones entre el cambio climático y los derechos humanos, el Consejo de derechos humanos de las Naciones Unidas acordó que el cambio climático supone una amenaza inmediata y trascendental para las personas y las comunidades de todo el mundo, y que este influye directamente en el disfrute pleno de los derechos humanos. La vinculación fue reconocida por la vía específica de las Resoluciones: La Comisión de Derechos Humanos de las Naciones Unidas adoptó la Resolución 2005/60, sobre los derechos humanos y el medio ambiente como parte del desarro1lo sostenible. El Consejo de Derechos Humanos adoptó la Resolución del 28 de marzo de 2008 sobre derechos humanos y cambio climático (A/HRC/ RES/7/23). Un año después, se adoptó la Resolución 10/4 de 25 de marzo de 2009 del Consejo de Derechos Humanos sobre derechos humanos y cambio climático, donde se requiere a la Oficina del Alto Comisionado de las Naciones Unidas para los Derechos Humanos, que realice un informe especial y que participe en los debates de la Asamblea General y de la Conferencia de las Partes sobre la Convención de Cambio Climático, procurando información sobre este y los derechos humanos, y se da la bienvenida para nombrar a un Relator Especial para que informe regularmente sobre los impactos que provoca el calentamiento global en los derechos humanos. El 3 de junio de 2008 la Asamblea General en el marco de la Organización de Estados Americanos (OEA) aprueba la Resolución sobre "Derechos Humanos y Cambio Climático en las Américas", AG/RES.2429 (XXXVIII-O/08). 
En 2008 aparece el primer informe sobre cambio climático, desastres naturales y desplazamiento humano elaborado por el Alto Comisionado de las Naciones Unidas para los Refugiados (ACNUR) y, a partir de este momento, la relación entre cambio climático, derechos humanos y migraciones es objeto de informes periódicos realizados por el Alto Comisionado para los Derechos Humanos, por el Alto Comisionado de las Naciones Unidas para los Refugiados y por el Relator Especial sobre las repercusiones del calentamiento global para los derechos humanos ${ }^{8}$.

La consolidación del nuevo paradigma del cambio climático basado en los derechos humanos sirvió como respuesta a un importante acontecimiento que tuvo lugar en 2007, una conferencia de pequeñas islas Estado convocadas por las Maldivas donde se adoptó la Declaración de Malé sobre la Dimensión Humana del Cambio Climático Global, en la que se pidió a la Conferencia de las Partes de la Convención Marco de Naciones Unidas sobre Cambio Climático que cooperara con la Oficina del Alto Comisionado de las Naciones Unidas para los Derechos Humanos y con el Consejo de Derechos Humanos de las Naciones Unidas para asesorarse sobre la relevancia de las conexiones entre cambio climático y derechos humanos (Vicente, 2018: 467-472).

Este nuevo enfoque que relaciona el cambio climático con los derechos humanos y las migraciones es un hecho muy esperanzador para los desplazados medioambientales. Como señala Oriol Solá Pardell,

\footnotetext{
${ }^{8}$ Mencionamos a modo de ejemplo algunos de los informes del relator especial: Informe del Experto independiente sobre "la cuestión de las obligaciones de derechos humanos relacionadas con el disfrute de un medio ambiente sin riesgos, limpio, saludable y sostenible", John H. Knox de 24 de diciembre de 2012, A/HRC/22/43 (2012). Informe del relator especial sobre "la cuestión de las obligaciones de derechos humanos relacionadas con el disfrute de un medio ambiente sin riesgos, limpio, saludable y sostenible", John Knox de 28 de diciembre de 2015, A/HRC/31/53 (2015). Informe del relator especial sobre la cuestión de "las obligaciones de derechos humanos relacionadas con el disfrute de un medio ambiente sin riesgos, limpio, saludable y sostenible", John H. Knox de 1 de febrero de 2016, A/HRC/31/52 (2016). Informe del relator especial sobre "la cuestión de las obligaciones de derechos humanos relacionadas con el disfrute de un medio ambiente sin riesgos, limpio, saludable" y sostenible de 19 de enero de 2017, A/HRC/34/49 (2017). También es importante mencionar el informe de varios relatores especiales para el Foro de Vulnerabilidad Climática titulado "Los efectos del cambio climático sobre el pleno disfrute de los derechos humanos", presentado el 1 de mayo de 2015 a la Conferencia de las Partes (COP) de la CMNUCC.
}

SCIO. Revista de Filosofía, n. ${ }^{\circ}$ 19, Noviembre de 2020, 63-99, ISSN: 1887-9853

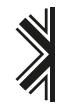


“en primer lugar, podría ayudar a mejorar el análisis de los impactos del cambio climático en la población humana vinculándolos a la materialización de más de 50 leyes internaciones de derechos humanos, como el derecho a la vida, a la salud, y a un nivel de vida adecuado, entre otros. En segundo lugar, este enfoque permitiría convertir en obligaciones jurídicas las hasta ahora simples declaraciones de intenciones y, en tercer lugar, facilitaría, a las comunidades más vulnerables al cambio climático, dejar de ser observadoras pasivas en las negociaciones climáticas para convertirlas en titulares de derechos" (Solá, 2012: 60).

En los conocidos como Acuerdos de Cancún, adoptados en la Conferencia de las Partes de la Convención Marco de las Naciones Unidas sobre Cambio Climático, celebrada en Cancún del 29 de noviembre al 10 de diciembre de 2010, se reconoció la importancia de las obligaciones de los derechos humanos para los Estados parte en la Convención Marco de Cambio Climático, y se impulsó la toma de medidas para mejorar "la comprensión, coordinación y cooperación con respecto al desplazamiento, la migración y la reubicación planeada". Mientras que la decisión de Doha de 2012 sobre pérdidas y daños impulsó iniciativas adicionales para adquirir una mejor comprensión de cómo los efectos adversos del cambio climático están afectando a los "patrones de migración, desplazamiento y movilidad humana". Una de las medidas puestas en marcha en el Marco de Adaptación de Cancún ha sido la Iniciativa Nasen (2011), implementada con la Agenda para la Protección de los Desplazados Fronterizos en el Contexto de los Desastres y el Cambio Climático (2015).

El primer acuerdo sobre el clima, que adopta la COP 21 en 2015 en París, reconoce en su preámbulo la vinculación entre el cambio climático, los derechos humanos y las migraciones. La principal ventaja de que en la COP21 se abordara el problema de los migrantes como resultado del cambio climático, como señalan A. C. Barbosa y T. C. Frota, sería una posible mayor facilidad para llegar a un acuerdo entre los estados del norte y del sur: los países desarrollados podrían ser ventajosos al otorgar una mayor protección a los "refugiados climáticos", la mayoría de los cuales provienen de países en desarrollo, a cambio de la aceptación de objetivos obligatorios para la reducción de sus emisiones de gases de efecto invernadero por parte de los países en desarrollo. Entre las desventajas encontradas al abordar este problema durante 
una conferencia sobre el clima, se señalan las siguientes: el tema no recibió la debida atención; en las discusiones en la COP no hubo participación de especialistas en temas migratorios; hubo falta de interés político debido a la crisis con los refugiados sirios en el tratamiento del problema; y se estableció una protección limitada solo a las víctimas de desastres ambientales relacionados con el cambio climático (Pereira y Frota, 2016: 62-63).

Los refugiados y desplazados climáticos son ya una realidad, señaló el director ejecutivo del PNUMA, Erik Solheim en el informe anual 2016 sobre la Acción Climática Mundial: "el creciente número de refugiados climáticos afectados por el hambre, la pobreza, la enfermedad y el conflicto constituirá un constante recordatorio de nuestro fracaso. La ciencia nos indica que debemos avanzar mucho más rápido". Una de las cuestiones más debatidas es si se han de llamar "refugiados climáticos" o "migrantes climáticos" cuando se trata de personas que se desplazan a causa del cambio climático. Al carecer de una definición adecuada, la Organización Internacional para las Migraciones (OIM) habla de migrantes climáticos y propone la siguiente definición: "Se conoce como migrantes por causas ambientales a las personas o grupos de personas que por culpa de cambios medioambientales ineludibles, súbitos o progresivos, que afectan de forma negativa sus vidas o sus condiciones de vida, se ven obligadas a dejar sus hogares, o deciden hacerlo voluntariamente. El desplazamiento puede ser temporal o permanente, en el interior de su país o al extranjero".

La palabra refugio como estatus de protección atribuible a personas que huyen de presiones medioambientales plantea problemas porque, como señala el estudio n. ${ }^{\circ} 31$ de la OIM sobre Migración y cambio climático (2008), no es la adecuada dentro del marco legal de la Convención de 1951 de las Naciones Unidas, y el Protocolo sobre el Estatuto de Refugiados de 1967 establece que el término refugiado debe restringirse a "una persona debido a fundados temores de ser perseguida por motivos de raza, religión, nacionalidad, pertenencia a determinado grupo social u opiniones políticas, se encuentre fuera del país de su nacionalidad y no pueda o, a causa de dicho temores, no quiera acogerse a la protección del país". Y, en la práctica, la comunidad internacional se resiste a cualquier ampliación de la definición de refugiado, porque los países desarrollados temen que al aceptar la ampliación del término a "refugiados 
climáticos", se vean obligados a conceder el mismo amparo a las personas que huyen a causa del cambio climático que a los refugiados políticos9.

Sin embargo, a pesar de que la utilización del término "refugiado climático" plantea problemas, se sigue utilizando. Estrictamente hablando, el refugiado se relaciona con el hecho de cruzar una frontera internacional, mientras que alguien que se desplaza dentro de su propio país es considerado como un desplazado interno.

De un lado, gran parte del desplazamiento humano ocasionado por el cambio climático sigue siendo de carácter interno y serían considerados desplazados climáticos. En este sentido, los resultados de la Conferencia Nansen sobre Cambio Climático y Desplazamientos en el siglo XXI de 2011, que se reflejan en los principios y en la iniciativa Nansen, tratan de ofrecer respuestas a los desplazamientos provocados por el cambio climático y otros peligros ambientales, ampliando así la protección y asistencia de los desplazados contenidos en los Principios Rectores de los Desplazamientos Internos de Naciones Unidas de 1998.

De otro lado, quienes cruzan la frontera y huyen a otros países podrían considerarse como refugiados climáticos. La idea de reformar la Convención de 1951 sobre el estatuto de los refugiados para incluirlos fue rápidamente rechazada, en parte por temor a socavar el frágil logro de la protección de los refugiados, pero también en parte porque las diferencias sustanciales entre los migrantes ambientales y los refugiados no parecen permitir tal analogía. A diferencia de la persecución, los factores ambientales generan principalmente la migración interna (es decir, la migración dentro de las fronteras nacionales) y los estándares emergentes de protección y asistencia a los desplazados internos son de gran relevancia. Sin embargo, al centrarse en los migrantes internacionales, algunos autores han preferido discutir posibles mecanismos de protección complementaria o subsidiaria, previamente desarrollados para personas que no pudieron regresar a su país de origen debido a conflictos armados o violencia generalizada, lo cual, argumentan, podría extenderse a migrantes ambientales o, al menos, a algunos de ellos (Benoît Mayer y Christel Cournil, 2016: 173).

\footnotetext{
${ }^{9}<$ https://publications.iom.int/system/files/pdf/mrs-31_sp.pdf $>$.
} 
En medio del bloqueo en el que se encuentra tanto el debate relativo al nuevo concepto como el relacionado con las normas que puedan dar respuesta a los problemas que plantea esta nueva realidad compleja y en ocasiones conflictiva, la vía del litigio climático y el desarrollo jurisprudencial de los tribunales nacionales e internacionales merece una especial atención como posible vía para la aceptación de nuevos conceptos y derechos. Como señalan Carlos Espósito y Alejandra Torres, "esta vía conceptual propone extraer la esencia común a las migraciones que en mayor o menor medida puedan ser relacionadas con el cambio climático mediante el recate del denominador común de todas ellas como elemento desencadenante de la movilización en todos los casos: la supervivencia" (Espósito y Torres, 2011: 80).

El caso de Ioane Teitiota en Nueva Zelanda, donde solicitó asilo y refugio, nos puede ilustrar sobre los problemas que sufren las poblaciones que cruzan la frontera en busca de protección internacional y las consecuencias de las decisiones que se toman por parte de los Estados y los organismos internacionales.

El señor Teitiota es nacional de la República de Kiribati, a quien los efectos del cambio climático y la subida del nivel del mar le obligaron a emigrar de su aldea natal de Tarawa a Nueva Zelanda con su mujer, y allí nacieron sus tres hijos. Cuando expiró su permiso temporal de residencia, Ioane Teitona solicitó la condición de refugiado o un estatuto de protección basado en la New Zeland Immigration Act de 2009. El Tribunal de Inmigración y Protección emitió una decisión, el 23 de junio de 2013, negativa sobre su solicitud de asilo, sobre la base de que la condición de "refugiado" del Acta debía interpretarse en el sentido de la definición de Refugiados de Naciones Unidas en la Convención de 1951. El Tribunal de Inmigración y Protección examinó el Programa de Acción Nacional de Adaptación de 2007 presentado por la República de Kiribati en virtud de la Convención Marco de las Naciones Unidas sobre el Cambio Climático, donde se declara que la gran mayoría de la población tenía medios de subsistencia que dependían en gran medida de los recursos ambientales. También en dicho Programa de Acción se describen problemas relacionados con el cambio climático, como la erosión costera que afecta a la vivienda, la tierra y la propiedad. Y aunque afirma que se estaban haciendo esfuerzos para diversificar la producción de cultivos, y que 
la mayoría de los cultivos nutritivos estaban disponibles y podrían ser preservados a largo plazo, sin embargo, reconoce que la salud de la población en general se había deteriorado, como indican las deficiencias de vitamina A, la desnutrición, la intoxicación por peces y otras dolencias que reflejan la situación de inseguridad alimentaria. También observa el Tribunal de Inmigración y Protección que el daño inducido por el cambio climático puede ocurrir a través de eventos de inicio repentino (como tormentas e inundaciones intensas) y procesos de inicio lento (como el aumento del nivel del mar, la salinización y la degradación de la tierra), y que ambos eventos pueden impulsar el movimiento transfronterizo de personas que buscan protección contra los daños relacionados con el cambio climático.

En la primera instancia el Tribunal reconoce que la normativa interna de Nueva Zelanda obliga a reconocer a los refugiados de acuerdo a lo establecido por la Convención de 1951, aunque dicho Tribunal no excluyó la posibilidad de que la degradación ambiental pueda "crear caminos hacia la Convención de Refugiados o la jurisdicción de personas protegidas". En este sentido, como subraya Mauricio Ferro, "al análisis del Tribunal destaca algo muy importante, pese a que en este fallo no cabe el otorgamiento de estatus como refugiado, esto no quiere decir que por cuestiones ambientales y por el cambio climático no se pueda conceder esta protección" (Ferro, 2016: 84).

La Corte de Apelación y la Corte Suprema rechazaron cada uno de los recursos posteriores de Ione Teitona en relación con el mismo asunto. La Corte Suprema de Nueva Zelanda denegó la apelación de la decisión del Tribunal el 20 de julio de 2015, en la que consideró que no había pruebas de que el Gobierno de la República de Kiribati no estuviera tomando medidas para proteger a sus ciudadanos de los efectos de la degradación ambiental en la medida de lo posible, y que el autor no enfrentaba daños graves regresando allí. Tampoco la Corte Suprema consideró que se había producido un error judicial sustancial. Sin embargo, la Corte no descartó la posibilidad de que la degradación ambiental resultante del cambio climático u otros desastres naturales pueda "crear un camino hacia la Convención de Refugiados u otra jurisdicción de personas protegidas".

El 15 de septiembre de 2015 el Sr. Teitona, representado por el abogado Michael J. Kidd, presentó una comunicación al Comité de Derechos Huma- 
nos, fundada en que la deportación a la República de Kiribiti por el Estado de Nueva Zelanda violó su derecho a la vida, en virtud del artículo 6 del Pacto Internacional sobre derechos civiles y políticos, porque había sido privado de sus medios de subsistencia debido a que sus cosechas habían sido destruidas por los depósitos de sal en el suelo, a las frecuentes e intensas inundaciones y fracciones de los diques, a la sobrepoblación, a las violentas disputas por la creciente escasez de tierra habitable en Tarawa, y a su falta de acceso al agua potable; y que las autoridades del Estado parte (Nueva Zelanda) no evaluaron adecuadamente el riesgo inherente a su deportación.

La queja (comunicación individual) de I. Teitona fue admitida a trámite por el Comité, ya que el impacto del cambio climático y el aumento del nivel del mar afecta a la habitabilidad de la República de Kiribati, y ello enfrentaba al autor a un riego real de menoscabo de su derecho a la vida, como resultado de la decisión del Estado parte de trasladarlo a Kiribati. Una vez admitida la queja, el Comité entró a examinar el asunto. En el examen de la comunicación el Comité observa, recuerda y considera:

Que la obligación de no extraditar, deportar o transferir de otro modo, de conformidad con el artículo 6 del Pacto, puede ser más amplia que el alcance del principio de no devolución en virtud del derecho internacional de refugiados, ya que también puede requerir la protección de los extranjeros que no tienen derecho al estatuto de refugiado. Por lo tanto, los Estados partes deben permitir que todos los solicitantes de asilo que reclaman un riesgo real de violación de su derecho a la vida en el Estado de origen tengan acceso a los procedimientos de determinación de la condición de refugiado u otros individualizados o grupales que podrían ofrecerles protección contra la devolución.

Que sin esfuerzos nacionales e internacionales sólidos, los efectos del cambio climático en los estados receptores pueden exponer a las personas a una violación de sus derechos en virtud de los artículos 6 o 7 del Pacto, lo que desencadena las obligaciones de no devolución de los estados emisores. Además, dado que el riesgo de que un país entero se sumerja bajo el agua es un riesgo tan extremo, las condiciones de vida en dicho país pueden volverse incompatibles con el derecho a la vida con dignidad antes de que se materialice el riesgo. 
Que el derecho a la vida no puede entenderse adecuadamente si se interpreta de manera restrictiva, que el derecho a la vida también incluye el derecho de las personas a disfrutar de una vida digna y a estar libres de actos $u$ omisiones que causarían su muerte antinatural o prematura. Que la protección del derecho a la vida requiere que los Estados adopten medidas positivas, y que los Estados parte pueden estar violando el artículo 6 del Pacto, incluso si tales amenazas y situaciones no resultan en la pérdida de vidas. Además, el Comité recuerda que la degradación ambiental, el cambio climático y el desarrollo insostenible constituyen algunas de las amenazas más apremiantes y graves para la capacidad de las generaciones presentes y futuras de disfrutar del derecho a la vida.

Después de estudiar a fondo el asunto, el Comité de Derechos Humanos concluyó que, sin perjuicio de la continua responsabilidad del Estado parte de tener en cuenta en futuros casos de deportación la situación en ese momento en la República de Kiribati y datos nuevos y actualizados sobre los efectos del cambio climático y el aumento del nivel del mar, el Comité no estaba en condiciones de sostener que los derechos del Sr. Teitona en virtud del artículo 6 del Pacto fueron violados tras su deportación a la República de Kiribati en 2015. Sobre la base de la información que se le proporciona, el Comité afirma que no está en condiciones de concluir que la evaluación de las autoridades del Estado parte de que las medidas adoptadas por la República de Kiribati serían suficientes para proteger el derecho a la vida del autor en virtud del artículo 6 del Convenant, eran claramente arbitrarias o erróneas a este respecto, o equivalían a una denegación de justicia. El Comité hace constar que las autoridades del Estado parte examinaron a fondo este problema y descubrieron que la República de Kiribati estaba tomando medidas de adaptación para reducir las vulnerabilidades existentes y aumentar la resistencia a los daños relacionados con el cambio climático.

La decisión adoptada por el Comité de derechos humanos el 24 de octubre de 2019, cuenta con dos votos disidentes, que no están de acuerdo con la posición alcanzada por el resto del Comité:

La opinión disidente del miembro del comité Valsilka Sancin surge del hecho de que el Estado parte no presentó pruebas de una evaluación adecuada del acceso del autor y de sus tres hijos al consumo seguro de agua potable. 
Sin embargo, según los informes expertos, entre otros, la relatora especial de las Naciones Unidas sobre el derecho humano al agua potable y al saneamiento, la señora Catarina de Alburquerque, después de su misión a Kiribati del 25 de julio de 2012, advirtió de que en Kiribati el Desarrollo Nacional de la Estrategia 2003-2007 y el Plan Nacional de Desarrollo 2008-2011 contienen políticas y objetivos de relevancia directa para el agua, pero que la Política Nacional de Recursos Hídricos de 2008 y las prioridades de una Política Nacional de Saneamiento 2010 establecidas para los primeros tres años aún no se han implementado. En estas circunstancias, concluye V. Sancin, corresponde al Estado parte, no al autor, demostrar que el autor y su familia, de hecho, disfrutarían de acceso a agua potable en Kiribati, para cumplir con el deber de proteger la vida de los riesgos derivados de los peligros naturales conocidos.

La opinión individual del miembro del Comité Ducan Laki Muhumuza es disidente con la posición alcanzada por el resto del Comité, porque el autor, Teitona, evidencia que el aumento del nivel del mar en Kiribati ha tenido como resultado la escasez de espacio habitable disponible y pone en peligro violentas disputas por la tierra, la degradación ambiental severa que resulta en la contaminación del suministro de agua, y la destrucción de cultivos alimenticios; cuando la familia del autor dependía en gran medida de la agricultura y la pesca de subsistencia. Desde su traslado a Kiribati, el autor y su familia no han podido cultivar; además, la tierra en Tarawa se ha inundado significativamente, y el autor y su familia al regresar a Kiribati han tenido problemas de salud graves, entre ellos el padecimiento por parte de uno de sus hijos de un caso grave de intoxicación sanguínea. Para Ducan Laki Muhumuza debería ser suficiente la situación del autor y su familia, junto a todos los hechos y circunstancias de la situación en el país de origen del autor, para revelar que el medio de vida no alcanza la dignidad que la Convención busca proteger. Y afirma que, aunque es loable que Kiribati esté tomando medidas de adaptación para reducir las vulnerabilidades existentes y abordar los males del cambio climático, mientras sigan siendo graves las condiciones, la vida y la dignidad de las personas siguen en peligro. Por último, concluye que la acción de Nueva Zelanda es más como "obligar a una persona que se está ahogando a subir a un barco que se hunde con la justificación de que, después de todo, hay otros viajeros a bordo". 


\section{§3. Menores, ADolescentes y Jóvenes en busCA de Refugio}

Aunque la mayoría de los migrantes de todo el mundo son adultos, los niños representan hoy la mitad de todos los refugiados (Informe Unicef, 2016). Todos los niños y niñas son sujetos vulnerables y, por ello, gozan de una protección especial. Antes que solicitantes de asilo, los refugiados o menores separados de sus familias son niños y, por tanto, sujetos merecedores de una protección especial. En primer lugar, les asiste la Convención de las Naciones Unidas sobre los Derechos del Niño que cuenta con un órgano de control de su cumplimiento: el Comité de los Derechos del Niño. En caso de sufrir temores de ser perseguidos tienen derecho a buscar protección en un Estado diferente al país de origen, tienen derecho a buscar asilo (art. 14 de la Declaración Universal de los Derechos Humanos de 1948 y Declaración sobre el Asilo territorial de 1967) y a la libre circulación de personas (art. 13 de la Declaración Universal de los Derechos Humanos). Y como personas que buscan protección, están amparadas por la Convención de Ginebra sobre el Estatuto de los Refugiados de 1951 y el Protocolo de Nueva York de 1967 y, por tanto, por el principio de no devolución. Como posibles víctimas de explotación sexual, estos menores están protegidos además por el Convenio del Consejo de Europa para la Protección de los Niños contra la Explotación y el Abuso Sexual, hecho en Lanzarote el 25 de octubre de 2007 y del que España es parte.

A los "menores extranjeros no acompañados" les asiste el derecho a la protección internacional, por ser prioritaria su condición de menor sobre el origen nacional. El menor extranjero que se encuentra fuera de su país sin la protección de ningún familiar o adulto responsable de su cuidado le amparan las normas nacionales e internacionales de protección de la infancia, que deberán ser interpretadas primando el interés superior del menor. Como afirma L. Carlos Nieto, "el argumento que sostiene la equivalencia entre la condición de menor y la entrada irregular no se sostiene jurídicamente. Es cierto que en apariencia pueden parecer dos lógicas enfrentadas, por un lado, la lógica de la "violación de la norma", que hace referencia a una migración en la que el menor ha entrado irregularmente en el territorio nacional y, por otro, la de la "protección a la infancia" por ser el extranjero menor de edad. Pero solo es aparente la colisión porque el estatuto de protección impide que se pueda 
aplicar a los menores la legislación de extranjería ante su entrada irregular" (Nieto, 2007: 118).

La situación de los menores refugiados resulta especialmente crítica y está implicando violaciones de la Convención sobre los Derechos del Niño, calificada como la Carta Magna de los derechos del niño, que fue aprobada por la Asamblea General de las Naciones Unidas el 20 de noviembre de 1989 (30 años después de ser aprobada la Declaración Universal de Derechos del Niño) y fue ratificada por España el 30 de noviembre de 1990. La protección de la infancia refugiada implica atender de manera primordial el interés superior del menor (artículo 3.1), e impone a los Estados dispensar una especial protección y asistencia cuando los menores se ven privados del medio familiar (artículo 20.1), dirigir todos sus esfuerzos y utilizar la cooperación necesaria para localizar a los padres o a otros miembros de su familia (artículo 22.2), y establece con amplitud el derechos de reunificación familiar en el artículo 10.1 cuando afirma que los Estados deben considerar de manera expeditiva las demandas de reunificación familiar de la solicitud hecha por un niño o por sus padres. Lo que no se cumple cuando se permite que los niños viajen solos y no se ponen en marcha todos los mecanismos disponibles para protegerlos y ayudarlos (Orihuela y Vicente, 2016: 140).

La ley prescribe que a los menores que buscan refugio hay que darles protección internacional, como menores especialmente vulnerables, en cualquier país de la UE con independencia de cuál sea el Estado por el que han accedido al territorio europeo. Para ello, es necesario que se les faciliten vías de acceso seguras; que se impida el alojamiento de los menores en los Centros de Internamientos de Extranjeros y en cualquier lugar que no reúna las condiciones adecuadas para asegurar el desarrollo holístico de los menores; y que se respeten escrupulosamente los derechos reconocidos a la infancia y adolescencia refugiada.

Una de las situaciones de vulnerabilidad que más preocupan son las informaciones de que pudiera haber menores en Centros de Internamiento de Extranjeros. La Fiscalía General del Estado deberá investigar la presencia en los CIE de menores de edad.

En algunos informes sobre los Centros de Internamiento de Extranjeros (CIE) se observa con frecuencia el internamiento de jóvenes que manifiestan 
ser menores de edad. En este sentido, en el Informe CIE 2018 del SJM (Servicio Jesuita Migrantes) se contabilizaron 20 casos en Madrid, 42 en Barcelona, 16 en Valencia y 15 entre Algeciras y Tarifa ${ }^{10}$. En el Informe CIE 2019 del SJM se contabilizaron en el CIE de Madrid-Aluche 13 que manifestaban ser menores, poniendo un caso en conocimiento del Comité de los Derechos del Niño. En el Centro de Internamiento de Barcelona-Zona Franca son 38 los internos que alegaban minoría de edad. En el CIE de Valencia-Zapadores, cabe destacar con preocupación los 4 que declaraban ser menores de edad: 2 de 16 y 2 de 17 años, de los que uno solo fue reconocido, puesto en libertad y trasladado a un centro de protección de menores. En el CIE de Algeciras-La Piñera y Tarifa-Isla de las Palomas, se dio seguimiento a los 9 posibles menores comunicándose con la directora del CIE, elevando quejas al Defensor del Pueblo o a la jueza de control: 3 pasaron al sistema de protección de menores, 2 confesaron su mayoría y 4 son dudosos ${ }^{11}$.

También preocupan especialmente los nuevos escenarios de Explotación Sexual Comercial de los menores y adolescentes que buscan refugio. Uno de los datos más alarmantes comunicado por la Oficina Europea de Policía (Europol) en 2016 fue la desaparición de 10.000 niños, niñas y adolescentes que llegaron a Europa huyendo de las situaciones de conflicto y pobreza de sus países de origen, sobre los que se desconoce su paradero actual. Muchos de ellos caen en manos de las mafias y son víctimas de explotación sexual, según constata el Informe de Save the Children de 2016 sobre Infancias Invisibles. Menores extranjeros no acompañados, víctimas de trata y refugiados en España.

En la frontera de México con Estados Unidos desde julio de 2017 el Gobierno del presidente Donald Trump separó a más de 5.400 menores de sus padres, según informó la Unión Americana de Libertades Civiles (ACLU), los abogados de la organización difundieron las cifras en la agencia de noticias Intra América News ${ }^{12}$. En junio de 2018 el periódico La Vanguardia publica la brutal imagen de niños “enjaulados” en la frontera entre México y Estados

\footnotetext{
${ }^{10}<$ https://sjme.org/wp-content/uploads/2019/06/Informe-CIE-2018-SJM.pdf $>$.

$11<$ https://sjme.org/wp-content/uploads/2020/06/Informe-CIE-2019-SJM_Diez-a\%C3\%B1os-mirando-a-otro-lado.pdf $>$.

$12<$ https://elintranews.com/usa/2019/10/25/aclu-mas-de-5-400-ninos-han-sido-separados-en-lafrontera-de-ee-uu/>.
} 
Unidos tras ser separados de sus padres ${ }^{13}$. A este grupo de menores de edad les asiste la Declaración Universal de Derechos Humanos, los Pactos Internacionales sobre Derechos Civiles y Políticos y Derechos Económicos, Sociales y Culturales, y la Convención de los Derechos de los Niños, que cuenta con el Comité de los Derechos de los Niños para controlar su cumplimiento en todos los lugares del mundo. Es, por ello, que todos los Estados están obligados a respetar y garantizar los derechos de la infancia, aunque no se sea parte de la Convención, como es el caso de Estados Unidos.

Estas incomprensiones y preocupaciones me llevaron en los primeros días de agosto de 2016, después de tener listo el borrador sobre refugiados del libro compartido La Crisis de los Refugiados y los Deberes de Europa, atraída por la llamada del punto de encuentro para juristas del campo de refugiados improvisado en el Puerto del Pireo y con la esperanza de llegar antes de su total desalojo, a los campos de refugiados de Atenas. De las más de cinco mil personas que habían estado alojadas durante meses no quedaba ninguna, un puerto ya preparado para el turismo. Después de tres días de búsqueda del paradero de estas gentes, algunas habían sido alojadas en squats o en albergues de tránsito en los barrios de Atenas, otras trasladadas a diferentes campos de refugiados, como Skaramagas, Lavrio, Patras, Malakasa, y otras muchas situadas en la periferia de la ciudad, la mayoría militarizados y con fuertes restricciones para poder entrar. Al final pude entrar en el campo de refugiados de Eleonas, a unos 20 kilómetros de Atenas, habitado en su mayoría por niños y mujeres, también adultos y ancianos profundamente entristecidos, y adolescente sin nada que perder y nada para ocupar su tiempo. Tras el desalojo del campo del puerto del Pireo, cientos de varones jóvenes no acompañados quedaron en las calles de Atenas, expuestos a la prostitución, las mafias y las drogas. Con el objetivo de dar respuesta y cubrir las necesidades de estos jóvenes en situación de calle, un grupo de jóvenes se asociaron y crearon Holes in the Borders, un proyecto de alternativa habitacional que logró abrir la primera vivienda para varones jóvenes solicitantes de protección internacional y refugiados sin hogar en noviembre de 2017.

\footnotetext{
${ }^{13}<$ https://www.lavanguardia.com/internacional/20180618/45217236554/ninos-jaulas-separacionfamilias-inmigrantes-eeuu.html $>$.
}

SCIO. Revista de Filosofía, n. ${ }^{\circ}$ 19, Noviembre de 2020, 63-99, ISSN: 1887-9853 
En Eleonas, la juventud de las mujeres y la cantidad de niños que acogían en sus precarios barracones es lo que más me impactó, cuando tuve el valor de entrar y mirar a una de estas mujeres a los ojos nos abrazamos en un llanto silencioso interrumpido al momento por las risas de muchos niños que nos rodearon, 8 niños y niñas, no eran todos suyos, solo tres, pero ya formaban una familia. Mi tarea en el campo era entretener a los niños, solo había una peluca morada para jugar, pero con ella hicimos cuentos y teatro, también tenía que recoger la basura que quedaba fuera de los contenedores para evitar que acudieran las ratas. Estuve pocos días, una semana, pero ese tiempo y mi compromiso con esas gentes siempre me ha acompañado y me acompañará toda la vida.

Al comienzo del nuevo curso académico 2017/2018 entré en contacto con personas de Murcia que habían estado también ese verano en los campos de refugiados, entre ellas Teresa Fuentes en el campo de refugiados de Ritsona, a una hora y media al norte de Eleonas, compartimos nuestro dolor, nuestra profunda emoción y la necesidad de actuar, sobre todo para ayudar a los niños y niñas y a los jóvenes no acompañados; su riesgo no nos dejaba dormir. El compromiso de Teresa la llevó pronto a crear una fundación, con nuestro amigo Joaquín el cura, llamada "amigos de Ritsona". Mientras mi compromiso fue más académico: participar en proyectos de refugiados, organizar congresos internacionales sobre infancia y adolescentes refugiados, hacer escritos de denuncia de estas situaciones al Comité de los derechos del Niño y al Consejo de Europa, e incluir el tema de los refugiados en todos los programas de las asignaturas que imparto en la Universidad de Murcia y en las actividades académicas.

En la UMU se despertaba el interés de los estudiantes por conocer esta realidad tan próxima. En 2018 Cristina Ortega, una de nuestras alumnas de grado en Derecho decidió que se iba a los campos de refugiados, después de hablar con ella me di cuenta de que nadie la iba a parar y hoy continúa en Atenas trabajando con jóvenes refugiados. Entró en el proyecto Holes in the Borders, y la asociación Amigos de Ritsona, de la que Teresa ya era secretaria, logró financiar dos de los tres apartamentos para varones jóvenes no acompañados. En 2019 Cristiana y Laila volvieron a la Universidad de Murcia con un grupo de jóvenes de diferentes países implicados en su proyecto, a contarnos su experiencia y nos presentaron un escalofriante reportaje, que luego ha publicado la organización Por causa Ahora, sobre la situación de los menores explota- 
dos sexualmente en Atenas (https://www.eldiario.es/desalambre/prostitucionmenores-migrantes-atrapados-atenas_1_3195409.html). Ahora cedo la palabra a Cristina, a Laila y a Natalia, y, luego, a Teresa, para que den voz a los que no la tienen pero que han confiado en nosotras, y con eso nos hacen grandes en la lucha y humildes en la vida, para hablar y actuar:

Laila Ben Chaouat El Fassi, Natalia Pelaz Belizón y Cristina Ortega Martínez han compartido su trabajo en el proyecto Holes in the Borders creado en Atenas en julio de 2016, con el desalojo del Pireo, y cerrado en mayo de 2020, con la COVID-19. El perfil del proyecto, "hombres jóvenes en situación de calle", se decidió porque existe una falta de preocupación y entendimiento de la situación de estos jóvenes por parte de la sociedad que, a partir de prejuicios e imágenes estereotipadas, desarrollan miedo hacia este colectivo. Estos jóvenes no acompañados, al cumplir los 18 años, se enfrentan a un gran riesgo de quedarse sin hogar. No son elegibles para permanecer en los programas de acogida disponibles para menores no acompañados, y se les obliga a trasladarse a campamentos o en la mayoría de casos a buscar otras alternativas porque los campamentos están llenos. Estos niños a los que pasan a llamar adultos de un día para otro, sin ninguna preparación previa, van a la calle, donde se exponen a ser captados por mafias y muchos de ellos empiezan a prostituirse para conseguir comida o una cama en un hostal en condiciones denigrantes donde comparten habitación con otros muchos.

La mayoría de los jóvenes varones refugiados que han viajado solos, sin apoyo familiar, no pueden acceder o no saben cómo acceder al sistema educativo griego para poder seguir estudiando. Su sufrimiento y la angustia psicológica a veces les conducen a trastornos de salud mental. Para los jóvenes y hombres, las emociones permanecen muchas veces encerradas dentro, debido a la visión prevalente de que ser un hombre de verdad consiste en ser duro y no mostrar miedo o tristeza. Usar drogas, fumar y beber alcohol es para algunos la forma más fácil de adormecer el dolor y de lidiar con estas emociones no reconocidas.

En 2016, poco después del desalojo del campo no oficial del puerto del Pireo, algunos de los jóvenes empezaron a desarrollar enfermedades de transmisión sexual tales como sífilis o clamidia, llegando algunos de ellos a admitir que se habían visto abocados a ejercer la prostitución para poder tener acceso 
a un hotel, comida o una tarjeta de teléfono para hablar con sus familias. Los hombres mayores les ofrecían dinero, comida, ropa o una cama donde poder dormir. Muchos de los jóvenes iban a la plaza Victoria o al parque de Pedion Areos donde se veían obligados a ejercer la prostitución al poco tiempo de llegar a Atenas porque no les quedaba dinero para poder sobrevivir, y apenas recibían apoyo de la comunidad internacional debido a que no entran en los criterios de vulnerabilidad. Además, son bien conocidas en Atenas las redes de prostitución de jóvenes varones migrantes, donde se les ofrece una cama en un motel o en una casa y comida, incluso un futuro pasaporte, a cambio de sexo.

En el caso de los hombres jóvenes que viajan solos, solicitantes o beneficiarios de protección internacional, su situación no es considerada vulnerable (salvo que sufran enfermedad crónica o determinados tipos de discapacidad), por lo que no tienen prioridad en el acceso a servicios tales como el alojamiento o la atención psicológica y no reciben el apoyo institucional necesario para salir de las circunstancias de explotación. Se encuentran abandonados por el Estado y por la sociedad, sufriendo racismo y teniendo grandes dificultades para encontrar un trabajo, no dejándoles en muchas ocasiones otra alternativa que la prostitución, que a nuestro parecer es un fenómeno inseparable de la trata de personas y de las situaciones de vulnerabilidad social. Así es como comenzó el proyecto Holes in the Borders, cuando descubrimos que «10 minutos 10 euros», una frase habitual de muchos de los chavales que dormían en la plaza de Victoria, era lo que les ofrecían por prostituirse.

\section{§4. LAS MUJERES: LAS MÁS AFECTADAS POR EL CAMBIO CLIMÁTICO Y LAS MEJORES AGENTES EN LA LUCHA CONTRA EL CAMBIO CLIMÁTICO}

La degradación ambiental y el cambio climático influyen en las distintas discriminaciones que sufren las mujeres y las niñas: el calentamiento climático empeora la situación económica de los más pobres, y entre ellos particularmente de las mujeres, las cuales representan el $70 \%$ de las personas que viven con menos de un dólar al día. El calentamiento climático degrada los recursos naturales de los cuales depende el subsistema de las familias en el medio rural, 
tarea que incumbe sobre todo a las mujeres, y que dificulta el encontrar agua y madera y la escolarización de las niñas. La inseguridad alimentaria crece con el cambio climático, lo que repercute más en las mujeres, que primero alimentan a sus hijos y a los más vulnerables y por ello sufren desnutrición. Las mujeres en muchos países se dedican a la agricultura, que supone el $80 \%$ de la alimentación, pese a que las sequías, tifones, ciclones, desertificación e inundaciones son amenazas para la agricultura. Las agricultoras tienen menos acceso a la propiedad, al crédito y a la tecnología, y a la formación, lo que impide que desarrollen su capacidad de iniciativa y adaptación. Los informes sobre mujer y clima en el ámbito internacional de las Naciones Unidas, como por ejemplo el Informe sobre Género y Cambio Climático en relación con la Convención Marco de Cambio Climático presentado en Bonn en 2019, y en el ámbito regional de Europa, donde destaca el Informe sobre Mujeres, Igualdad de Género y Justicia Climática aprobado en 2017 por el Parlamento Europeo, reconocen que las mujeres llevan la peor parte de las consecuencias del cambio climático y, al mismo tiempo, que las mujeres somos capaces de protagonizar el cambio de modelo social y ecológico que se necesita para enfrentar la lucha por el clima.

Sí bien, como acabamos de exponer, las mujeres son sujetos especialmente vulnerables a los fenómenos climáticos extremos, esta discriminación se agrava con las migraciones climáticas. Las refugiadas climáticas, tanto en las carreteras como en los campos de refugiados, se enfrentan a más peligros: agresiones, violaciones, maltrato, redes criminales que las reclutan para la trata y la prostitución, y la violencia machista. En este sentido, la recomendación general n. ${ }^{\circ} 32$ sobre las dimensiones de género del estatuto de refugiada, el asilo, la nacionalidad y la apatridia de las mujeres, del Comité para la Eliminación de la Discriminación contra la Mujer, insiste en que la política migratoria debe tener en cuenta las especiales condiciones de vulnerabilidad de las mujeres, y los Estados están obligados a la adopción de políticas y programas específicos y efectivos orientados a mejorar la posición de la mujer y lograr esa igualdad de facto, incluida, cuando proceda, la adopción de medidas especiales de carácter temporal.

En un principio, nos dice Teresa Fuentes, cofundadora y secretaria de Amigos de Ritsona, los campos de refugiados estaban diseñados para ser zonas 
de tránsito hasta que se formalizaran los papeles en los países de acogida, sin embargo, esto no ha ocurrido, se han convertido en campos permanentes, lo que ha provocado, entre otras cosas, que las mujeres den a luz en ellos. El trato para ellas no es diferente al resto de personas que malviven allí, van al hospital a dar a luz y lo antes que pueden las envían de vuelta a los campos, da igual si han tenido que pasar por una cesárea o han tenido algún tipo de complicación. A los pocos días de dar a luz, están cocinando, lavando los platos con mangueras improvisadas en el suelo, cuidando de todos los hijos e hijas mientras dan pecho a su recién nacido.

Teresa ha visitado y trabajado desde 2016 en diferentes campos de refugiados y proyectos sobre el terreno, en especial en el ámbito de las mujeres refugiadas; ella nos cuenta: hace dos años visitamos por primera vez el campo de personas refugiadas de Moria, en la isla de Lesbos, y lo que vimos allí nos dejó sin aliento. Es el campo de personas refugiadas más grande de toda Europa. Un campo diseñado para albergar a 2500 personas y que ha llegado a superar las 20.000. De todas las historias que he escuchado hay algunas que sé que siempre permanecerán en mi memoria, como la de una mujer afgana que lloraba desconsolada mientras nos contaba que llevaba 15 días durmiendo en la playa con sus dos pequeños, porque temía ser violada por la noche dentro del campo de refugiados. Su marido había muerto en Afganistán y salió de su país para poner su vida y la de sus pequeños a salvo, no quería que sus hijos vivieran entre tanta violencia; hacia dos días, su hijo de apenas 5 años, le había pedido un cuchillo, al preguntarle para qué lo necesitaba, su hijo le dijo que para defenderse. La realidad es que las violaciones son constantes dentro del campo de Moria, las mujeres tienen que dormir con pañales ya que si salen de las tiendas a mitad de la noche pueden ser violadas, algo que también ocurre con frecuencia con los más pequeños. Un psiquiatra italiano de MSF nos contaba que asiste a pequeños con rotura de esfínteres para toda su vida. Toda esta situación está provocando que más de un centenar de personas al mes intenten quitarse la vida, entre ellos, pequeños a partir de 5 años, algo que denunciamos junto con Save the Children.

De las organizaciones que hemos conocido en terreno, Rowing Together es una ONG española que comparte espacio junto con MSF y se encarga de cubrir la asistencia ginecológica, y nos interesamos por saber cuáles eran 
las condiciones de las mujeres en el campo. Una de las cosas que nos dejó rotas fue cuando nos contaron que la mayoría de las mujeres que provenían de África habían sido violadas en el trayecto y llegaban embarazadas o con enfermedades de transmisión sexual.

Un día que estábamos en el proyecto de The Hope Project, una de las ONG con la que, desde la Asociación Amigos de Ritsona, colaboramos de forma habitual, observamos cómo una mujer congoleña con sus tres hijos, uno de ellos recién nacido, estaba en el proyecto recogiendo algunos productos básicos, como una silleta para el más pequeño, pedía leche en polvo para el recién nacido, pero en la ONG le decían que no habían llegado donaciones de leche, al igual que los pañales, son de los productos que más escasean en la isla debido a su alto coste. Al oírla, decidí llevarla en coche al campo de Moria, que está a unos $4 \mathrm{~km}$ del proyecto. En el coche aproveché para preguntarle por su situación. Contaba que a su marido lo degollaron en el Congo, que tuvo que salir corriendo con sus tres hijos para ponerlos a salvo. Mientras ella hablaba, su hijo mayor, de apenas 12 años, miraba por la ventana del coche con la mirada más triste que he visto jamás, en ese momento recordé lo que nos contaron en Rowing Together.

En la conexión entre el cambio climático, el género y las migraciones existe un eje común que está en sus raíces, explica Beatriz Felipe Pérez: las estructuras de poder, el sistema capitalista y el patriarcado, y los migrantes climáticos son, en definitiva, migrantes del capitalismo. En definitiva: "las mujeres y niñas sufren de manera diferenciada los impactos del cambio climático en general y de las migraciones climáticas en específico. Las lógicas de género con frecuencia las relegan a un segundo plano a la hora de tomar decisiones y de recibir beneficios, pero les otorga un papel protagonista como responsables de los cuidados y receptoras de las cargas y de las peores consecuencias" (Felipe, 2019: 51).

La realidad de la desigualdad y la discriminación que sufren las mujeres en el contexto del cambio climático y las migraciones han fomentado como objetivo prioritario promover la participación de las mujeres en todas las decisiones que tomen con relación al cambio climático, y poner de manifiesto el valor de las mujeres como agentes de cambio en la lucha por el clima. Aunque los avances en la igualdad de género son muy lentos, se trata de un camino 
que ya se ha iniciado. En la Cumbre de la Tierra de 1992 se reconoció el saber hacer tradicional de las mujeres y su derecho a la Tierra, y en la Agenda de Desarrollo Sostenible 2030 que se adopta en la Cumbre de la Tierra de Nueva York de 2015 se plantea el objetivo 5 de igualdad de género. Aunque ya había objetivos de género en los Objetivos de Desarrollo del Milenio (ODM) del año 2000. En las Conferencias de las Partes de la Convención del Cambio Climático se hace mención a las mujeres por primera vez en 2010, y en los llamados Acuerdos de Cancún se dice que en las medidas de adaptación y mitigación se tienen que tener en cuenta a las mujeres por su especial situación de vulnerabilidad, pero las mujeres no somos un grupo minoritario, somos la mitad de la humanidad. Tras Cancún se aprobó en Lima el Programa de Trabajo en Género, que fue el que se extendió hasta 2019 y, en su marco, se aprobó el Plan de Acción. En el Acuerdo de París hay una referencia a la igualdad y empoderamiento de las mujeres; en la COP 22 en Marraquech se acuerda ampliar el Plan de Acción Mujer y Clima, y en la COP23 en Bonn en noviembre de 2017 se adopta por fin el Plan de Acción Mujer y Clima (Vicente, 2020).

\section{§5. Algunas Propuestas y Reflexiones}

UNA: Deslegitimar la hegemonía del modelo neoliberal de triunfo del mercado e impulsar un modelo de cohesión social y sostenibilidad ecológica que ponga en el centro a las personas y al medio ambiente; en este sentido, hay que cambiar la política de frontera, represión y depredación por una política de salvamento, acogida, reubicación y protección, y avanzar hacia una economía de desarrollo sostenible.

Actualmente el mundo se enfrenta a las incidencias del cambio climático en los desastres naturales, alimentos, energía, mercados financieros y depresión económica mundial. Y aunque no se pueden predecir exactamente el momento y la magnitud de estos fenómenos, lo que sí se puede es cambiar el modelo económico basado en el crecimiento ilimitado por un modelo que entiende el crecimiento en el sentido del desarrollo sostenible, un concepto que se ha ido ampliando y configurando en las Cumbres de las Naciones Unidas, y poner en marcha la economía del cambio climático (Informe Stern, 2006 sobre la economía del cambio climático). 
El objetivo del desarrollo sostenible y su vinculación con el desarrollo social, el cambio climático y los derechos humanos se consolidan en la Cumbre de las Naciones Unidas sobre Desarrollo Sostenible de 2015 en Nueva York. La adopción de la Agenda de Desarrollo Sostenible de 2030, que plantea un Plan de Acción de desarrollo mundial con 17 objetivos durante los próximos quince años, incluye la Acción por el clima como objetivo trece.

DOS: Un compromiso efectivo y vinculante sobre la puesta en marcha de una acción colectiva de medidas de mitigación y de adaptación, que pongan freno al cambio climático. La acción climática compagina mitigación y adaptación. La mitigación es la intervención antropogénica para reducir las fuentes de los gases de efecto invernadero o mejorar sus sumideros, y la adaptación es el ajuste entre los sistemas humanos y naturales en respuesta a las condiciones climáticas reales o esperadas y sus efectos, lo que modera el daño o explota oportunidades beneficiosas.

Una dificultad fundamental para impulsar una acción colectiva contra el cambio climático es que aquellos que deben esforzarse en mayor medida para detener las emisiones de gases de efecto invernadero son precisamente los menos afectados en comparación por las repercusiones del calentamiento global. "Es por eso que las naciones industrializadas tienen pocos incentivos para actuar; nuestra voluntad se ve arruinada por nuestro propio interés" (Gemenne, 2015: 70).

La acción climática está unida al movimiento mundial por una justicia climática y al movimiento de la Economía del Bien Común (Christian Felber, 2012), donde el objetivo de la economía no sea aumentar la acumulación del capital y el beneficio a costa del deterioro de los derechos sociales y ecológicos, sino que su objetivo sea satisfacer las necesidades de las personas y de los ecosistemas y para ello se necesita poner en el centro los Derechos Humanos y la protección de la Naturaleza.

TRES: Una apertura de las fronteras, no una fortaleza amurallada frente a los refugiados, lo que significa un avance en democracia y derechos humanos y prepararnos para unos movimientos de población que son ya inevitables.

Primar las operaciones de acogida y salvamento sobre las operaciones de defensa de frontera. Crear vías de acceso seguras y legales para las personas necesitadas de protección internacional. Facilitar la llegada de los demandantes 
de asilo para poner fin al negocio de las mafias que trafican con personas, fortalecer y ampliar el acceso a los servicios básicos para las situaciones de vulnerabilidad. Y crear un sistema operativo de rescate para evitar la constante muerte de personas, en su mayoría mujeres y menores, en el mar Mediterráneo.

CUATRO: Que Europa cumpla con sus compromisos de reubicación (personas desde Italia y Grecia) y asentamiento (personas procedentes de Oriente Medio y África) de las personas en situación de refugio. Ampliación del procedimiento de reagrupación familiar y los visados humanitarios. Que se atienda de forma específica las situaciones de especial vulnerabilidad y violencia, y que se les facilite la asistencia que precisan según sus necesidades y derechos.

Según la Comisión Española de Ayuda al Refugiado en España, en 2019 este fue el tercer país de la Unión Europea que registró un mayor número de solicitantes de asilo, al tiempo que disminuyó el porcentaje de personas que lograron protección internacional (Informe CEAR, 2019).

CINCO: Atender el derecho a la reparación y la compensación por las acciones que han provocado su huida y necesidad de protección internacional. Reconocer el "derecho al retorno" que tienen estas personas que se encuentran en una situación de huida, a quienes se les ha provocado una situación de ruptura con su entorno social, y hay que establecer normas para que puedan retornar.

SEIS: Acceso a la justicia para que los ciudadanos puedan denunciar el incumplimiento de las obligaciones y deberes de sus representantes. Los ciudadanos necesitan vías jurídicas para hacer cumplir a los Gobiernos las obligaciones que derivan de los derechos humanos y de las normas internacionales. Se precisan acciones jurídicas en poder de la sociedad civil para exigir el cumplimiento del derecho internacional, esto es, nuevos instrumentos que permitan una acción a la ciudadanía para poder exigir ante los tribunales de justicia europeos e internacionales el cumplimiento de la legalidad internacional y de los derechos humanos por parte de nuestros gobiernos.

SIETE: Para las migraciones climáticas es necesario un marco de protección jurídica que ahora no existe; en este sentido la doctrina jurídica tradicional del derecho internacional y de los derechos humanos es insuficiente 
para dirimir los problemas de los migrantes climáticos. Para resolver el vacío se proponen dos soluciones: una, ampliar la definición de refugiados de la convención de 1951 para añadir a los refugiados medioambientales, aunque no es deseable porque se considera una maniobra peligrosa, e incluir esta ampliación en los sucesivos instrumentos del Protocolo de Kioto, el Acuerdo de París y en la Convención del Clima. Y la otra propuesta, establecer un nuevo acuerdo internacional centrado en los problemas de los migrantes climáticos, en este sentido y ante la diversificación de la protección de las personas que están obligadas a huir, sería necesario un nuevo convenio internacional que recoja todas las formas de protección internacional.

\section{REFERENCIAS BIBLIOGRÁFICAS}

Abellán, B. (2020), ¿Protege el Marco Jurídico Europeo a los Migrantes Climáticos? Disponible en: <https://migracionesclimaticas.org/protege-elmarco-juridico-europeo-a-los-migrantes-climaticos/>.

ACNUR (2020). Tendencias Globales. Desplazamiento Forzado en 2019. Disponible en: <https://acnur.org/5eeaf5664\#_ga=2.124720137.2076242601 .1593590645-58030701.1592906904>.

ACNUR (2018). Pacto Mundial sobre los Refugiados. Informe del Alto Comisionado de las Naciones Unidas para los Refugiados, A/73/12 (Part II). Nueva York. Disponible en: <https://www.unhcr.org/gcr/GCR_Spanish.pdf > .

ACNUR (2017). Cambio Climático, Desastres y Desplazamientos. Suiza. Disponible en: $<$ https://www.acnur.org/5d4c9b7f4.pdf $>$.

ACNUDH (2018). Los efectos de evolución lenta del cambio climático y la protección de los migrantes transfronterizos. Ginebra. Disponible en: <https://disasterdisplacement.org/portfolio-item/los-efectos-deevolucion-lenta-del-cambio-climatico-y-la-proteccion-de-los-migrantestransfronterizos>.

Barbosa Pereira Matos, A. C., Frota Mont'Alverne, T. C. (2016). O regime Internacional do clima e a proteção aos "refugiados climáticos": quais desafios da COP 21? Revista de Direito Internacional 13(2), 55-76. 
CEAR (2020). Las Personas refugiadas en España y Europa. Comisión Española de Ayuda al Refugiado. Madrid. Disponible en: $<$ https://www.cear. es/informe-cear-2020/>.

De Lucas, J. (2015). Mediterráneo: el naufragio de Europa. Valencia: Tirant Humanidades.

Espósito, C., Torres Camprubí, A. (2011). Cambio climático y Derechos Humanos: el desafío de los "nuevos refugiados". Relaciones Internacionales (17), 67-86.

Felipe, B. (2019). Perspectiva de Género en Las Migraciones Climáticas. Madrid: ECODES.

Ferro, M. (2016). El reconocimiento del Estatuto de Refugiado por la afectación a Derechos Fundamentales como consecuencia del Cambio Climático. Observatorio Medioambiental (19), 71-89.

Gemenne, F. (2015). Una buena razón para hablar de los "refugiados climáticos". Migraciones Forzadas (49), 70-71.

IDMC (2015). People displaced by disasters. Global Estimates 2015.Internal displacement monitorin centre. Norwegian Refugee Council (NRC). Ginebra. Disponible en: <https://www.internal-displacement.org/sites/default/ files/inline-files/20150713-global-estimates-2015-en-v1.pdf>.

Mayer, B., Cournil, Christel. (2016). Climate change, migration and human rights. Towards gropu-specific protection? En Ottavio Quirico y Mouloud Boumghar (eds.), Climate Change and Human Rights. An international and comparative law perspective. Routledge.

Nieto, L. C. (2007). La reagrupación familiar como pretexto: los menores extranjeros no acompañados. En María del Carmen Barranco, María Isabel Garrido y Juan Gilló (coords.), El derecho del niño a vivir en su propia familia. Madrid: Save the Chidren.

OIM (2008). Serie de Estudios Sobre La Migración, $N^{o} 31$. Ginebra. Disponible en: <https://publications.iom.int/system/files/pdf/mrs-31_sp.pdf $>$.

Orihuela, E., Vicente T. (2016). Mujeres, Infancia y Refugio. En Natalia Morales y Héctor Romero (coords.), La crisis de los refugiados y los deberes de Europa. Madrid: La Catarata. 
Rivillo Torres, J. (2016). Refugiados climáticos y territorios de frontera. REDES.COM (13), 167-195.

Scott, M. (2020). Cambio Climático, Desastres y la Convención sobre el Estatuto de los Refugiados. Disponible en: <https://migracionesclimaticas. org/cambio-climatico-desastres-y-la-convencion-sobre-el-estatuto-de-losrefugiados/>.

SJM (2020). Diez años mirando a otro lado. Servicio Jesuita a Migrantes. Madrid. Disponible en: <https://sjme.org/wp-content/uploads/2020/06/ Informe-CIE-2019-SJM_Diez-a\%C3\%B1os-mirando-a-otro-lado.pdf $>$.

SJM (2019). Discriminación de Origen. Servicio Jesuita a Migrantes. Madrid. Disponible en: $<$ https://sjme.org/wp-content/uploads/2019/06/Informe-CIE2018-SJM.pdf>.

Solá, O. (2012). Desplazados medioambientales. Una nueva realidad. Cuadernos Deusto de Derechos Humanos (66). Bilbao.

Vicente, T. (2018). Justicia climática y derechos humanos: mirando al futuro. En Pablo Jarauta y Pedro Medina (eds.), Francisco Jarauta en las fronteras de Babel. Madrid. Instituto Europeo Di Design (IED).

Vicente, T. (2020). Las mujeres, defensoras de la igualdad y el cuidado de la naturaleza. Iqual, Revista de Género e Igualdad (4), pendiente de publicación. 